\title{
Kearifan Tradisional sesudah Upacara Pemakaman "Pinadanoan" pada Masyarakat Tombatu
}

\author{
Maxi Kojong \\ Fakultas Ilmu Budaya \\ Universitas Sam Ratulamgi
}

\begin{abstract}
In society, the behavior of daily life is influenced by the traditions inherited from the ancestors that were carried out long ago. Of the many traditions that are passed down, there are still traditions that still survive or are sustainable or are still being carried out in life. In the Tonsawang tribal community, it is full of traditions. One of the traditions that are still carried out is that after the funeral, there are several traditions that must be carried out by the nuclear family who died. One of the traditions is bathing in the river, washing away the clothes worn. This tradition has been carried out since time immemorial, and is the legacy of the ancestors of the Tonsawang tribe. The purpose of this study is to describe how the traditions are carried out after the funeral. Describe the factors that led to the implementation of the tradition. The last is to describe what the meaning of doing these traditions is. This research uses descriptive analysis.
\end{abstract}

Keyword : Kearifan Tradisional, "Pinadanoan" Masyarakat Tombatu

\section{Pendahuluan}

Pada umumnya setiap etnik mempunyai tradisi atau kebiasaan-kebiasaan yang merupakan warisan turun-temurun. Tradisi adalah suatu pola atau perilaku atau kepercayaan yang telah menjadi bagian dari suatu budaya yang telah lama dikenal sehingga menjadi adat istiadat dan kepercayaan secara turun temurun. (Soekanto 1993 : 520). Setiap tradisi pada umumnya mempunyai nilai-nilai keluhuran budi yang tinggi dan seringkali tidak tersentuh oleh agama dan budaya Global. Jepang mempunyai tradisi yang sangat kental dan berdampak positif ketika restorasi Meiji dan modernisasinya, sehingga Jepang menjadi negara industri pertama dan termaju di daratan Asia sejak abad 19. Ada juga tradisi yang tidak berpihak kepada nilai kebaikan bahkan bertentangan dengan nilai hak asasi manusia secara universal. Hal ini dapat dilihat pada pertarungan para Gladiator yang mempertontonkan kekuatan dan kekejian di depan para raja dan golongan bangsawan, dan lain-lain. Selanjutnya kearifan lokal mempunyai kaitan yang sangat erat dengan kebudayaan tradisional pada suatu tempat, serta dalam kearifan lokal terkandung suatu pandangan atau aturan agar suatu masyarakat mempunyai pijakan dalam menemukan sesuatu tindakan seperti prilaku masyarakat dalam kehidupan sehari-hari. Pada umumnya etika dan nilai moral yang terkandung dalam kearifan lokal diajarkan turun temurun, diwariskan dari generasi-ke generasi melalui sastra lisan antara lain (dalam bentuk pepatah dan peribahasa folklore) dan manuskrip ( Suyono, 2003). 
Warisan kearifan lokal yang telah diwariskan tersebut merupakan kebudayaan yang seharusnya dijaga dan dilestarikan. Masyarakat suku Tonsawang atau Tombatu, dalam kehidupan sehari-hari masih banyak menggunakan tradisi-tradisi warisan nenek moyang. Salah satu tradisi yang masih banyak dilakukan yaitu kegiatan memandikan anggota keluarga inti yang berduka di sungai yang dalam bahasa Tonsawang "Pinə?danoan". Dalam pengamatan penulis, kegiatan memandikan keluarga yang berduka di sungai "Pinə?danoan", belum pernah seorangpun yang menulis, atau menelitinya. Berdasarkan hasil survei penulis pada beberapa desa yang ada di kecamatan Tombatu raya, kegiatan tradisi memandikan keluarga yang berduka di sungai sudah semakin sedikit dilakukan. Untuk itu penulis merasa hal ini perlu diangkat dan diteliti sebelum kegiatan tradisi ini hilang atau tidak di lakukan lagi. Alasan semakin sedikit yang melakukan kegiatan tradisi ini, karena pengaruh masuknya golongan agama, dan modernisasi pola pikir berdampak pada terkikisnya praktek tradisi-tradisi yang telah lama dilakukan sejak dahulu.

\section{Rumusan Masalah}

Berdasarkan latar belakang diatas, maka masalah yang diangkat yaitu :

1. Bagaimana tradisi "Pinə?danoan"sesudah acara Pemakaman jenazah pada masyarakat di Tombatu?

2. Faktor-faktor apa yang menyebabkan dilaksanakan tradisi "pinə?danoan sesudah acara pemakaman?

3.Apa makna dilaksanakan tradisi "pinə?danoan"?

\section{Tujuan Penelitian}

Penelitian ini bertujuan :

1. Mendekripsikan tradisi "Pinə?danoan"sesudah acara Pemakaman Jenazah.

2. Mendeskripsikan faktor-faktor penyebab dilaksanakan tradisi "Pinə?danoan".

3.Mendeskripsikan makna yang terkandung dalam kegiatan tradisi "Pinə?danoan"

\section{Manfaat Penelitian}

Manfaat yang terdapat pada penelitian adalah:

1. Manfaat teoritis yaitu memperluas pengetahuan tradisi budaya yang berkaitan dengan kegiatan memandikan keluarga yang berduka "Pinə?danoan" pada masyarakat suku Tonsawang.

2. Manfaat praktis, dapat membantu memahami salah satu tradisi yang masih dilakukan suku Tonsawang berkitan dengan kegiatan "Pinə?danoan". 


\section{Tinjauan Pustaka dan Kerangka Teori}

\section{Tinjauan Pustaka}

Penelitian menegenai tradisi "pinəPdanoan" pada masyarakat suku Tonsawang sepengetahuan penulis belum pernah dilakukan. Selanjutnya informasi penelitian yang berkaitan dengan suku Tonsawang, yaitu Esser dalam Salea (1996), Salzner dalam Salea (1982) yang selanjutnya Marifield dan Salea (1996) menempatkan bahasa Tonsawang dalam kelompok bahasa Minahasa, Salea dkk(1982) membahas Struktur Bahasa Tonsawang, Saud (1987) Proses morologi Bahasa Toundanow/Tonsawang, Salea dkk (2003) Kamus Tonsawang-Indonesia, Rorong (1996) Sakit dan Sehat menurut Pandangan Masyarakat bahasa Tonsawang.

\section{Kerangka Teori}

Penelitian ini mengkaji tentang tradisi memandikan keluarga inti yang berduka sesudah acara pemakaman, 'pinə?danoan". Pendekatan yang digunakan yaitu pendekatan etnosains yaitu pendekatan etnosains yang menyangkut usaha si peneliti memandang gejala sosial tidak dari sudut dirinya sebagai peneliti, melainkan dari kacamata orang yang terlibat di dalamnya. Selanjutnya peneliti tidak bermaksud menilai apakah pandangan mereka salah atau benar, baik atau buruk, tetapi mencoba memahami dan menjelaskan pandangan-pandangan mereka. (Ahimsa, 1985:104). Selanjutnya dalam menganalisis dan mengungkapkan pola pikir masyarakat digunakan teori Aspek menurut Comrie (1978) yaitu mengklasifikasikan segala aspek ke dalam perfektif dan imperfektif. Dan dalam menggambarkan pola pikir pelaku kegiatan tradisi "pinə?danoan" digunakan metode deskriptif.

\section{Pembahasan}

\section{Tradisi “Pinə?danoan”sesudah acara Pemakaman jenazah pada masyarakat di Tombatu}

Bahasa dan kebudayaan ibarat dua sisi pada mata uang logam, dimana bahasa dan kebudayaan merupakan suatu yang tidak dapat terpisahkan satu dan lainnya. Demikian pula Pada masyarakat Bahasa Tonsawang, dalam kehidupan sehari-hari tidak terlepas dari adat istiadat, atas kebiasaan-kebiasaan yang merupakan warisan nenek moyang. Pada Masyarakat Suku Tonsawang, ketika terjadi kematian, semua masyarakat sekitar terjadinya kedukaan secara bergotong royong, segera mendirikan bangsal duka, mengantar beras, ikan, bumbu-bumbu, rokok, cap Tikus, yang akan dipakai menyiapkan hal-hal yang berkaitan dengan persiapan acara pemakaman.

Sesudah Upacara Pemakaman, ada beberapa tradisi yang dilakukan oleh anggota keluarga inti dari yang telah meninggal. Tradisi-tradisi tersebut yaitu, melakukan pantanganpantangan yakni "selama setahun, keluarga yang berduka wajib menggunakan pakaian hitam, misalnya perempuan bagian atasan harus hitam, kalau rok, bisa warna lain, dengan catatan, tidak boleh memakai bawahan warna merah. Laki-laki juga, kemeja atau kaus harus warna hitam tetapi celananya boleh warna lain selain hitam asalkan bukan warna merah. Laki-laki maupun 
perempuan, keluarga inti selama setahun, tidak boleh menyisir rambut, kalau duduk, hanya boleh duduk sendiri di kursi tunggal,bagi perempuan, tidak boleh mencari kutu, tidak boleh menggunakan alat-alat make up bagi perempuan. Pantangan-pantangan makanan, misalnya, tidak boleh makan makanan sayuran daun pepaya, jenis daging juga, tidak boleh makan daging yang diasinkan dengan garam dan lainya.

Hal yang paling menonjol dari kegiatan-kegiatan sesudah acara pemakaman yaitu Kegiatan "Pinədanowan" 'memandikan'. Kegiatan ini harus dilakukan seluruh keluarga inti. Rangkaian kegiatan "Pinədanowan” sebagai berikut :

1. Setelah mayat di kebumikan,misalkan yang meninggal istri, maka si suami, dan anakanak harus dimandikan di sungai oleh orang yang tahu memandikan. Kegiatan "Pinədanowan" dilakukan pada besok subuh sekitar jam empat atau jam lima, orang yang bertugas memandikan keluarga yang berduka, menuju rumah keluarga yang berduka, menjemput, kemudian bersama-sama menuju sungai. Dalam perjalanan menuju sungai, orang yang akan memandikan keluarga yang berduka, memetik pucuk daun jarak sebanyak 3 pucuk yang akan dipakai pada kegiatan "Pinədanowan".

2. Setibanya di sungai, misalnya si duda/janda/anak-anak, turun ke sungai bersama-sama dengan orang yang biasa memandikan. Orang yang akan dimandikan setelah turun ke sungai, langsung duduk dan menghadap ke arah bawah aliran sungai. Orang yang bertugas memandikan, berdiri di belakang orang yang akan dimandikan. Jarak Posisi orang yang bertugas memandikan(balian) dan yang akan dimandikan sekitar 2 meter.

3. Orang yang bertugas memandikan, memakai kedua tangannya, mengambil air lalu menyiramkan kepada orang yang dimandikan sebanyak 3 kali. Setelah disiram sebanyak 3 kali, orang yang memandikan mengambil pucuk daun jarak, kemudian digosok diputar sebanyak 3 kali di bagian kepala, turun ke pundak, bagian punggung bagian bokong, sambil mengucapkan ungkapan "nde kou belolahan i karoangnu na'am ko maganggu-ganggu we' be sia apa-apaan banam tampanu maknanya, 'karena engkau telah meninggalkan suami/istrimu, maka, jangan lagi engkau menggangu-ganggu lagi dia, karena engkau telah mempunyai tempat'.

4. Kemudian melempar ke aliran sungai sambil mengucapkan ungkapan mohonem hou, lumas oho be sia,'(pucuk pohon jarak) Setelah itu, orang yang dimandikan berbalik badan menghadap ke arah hulu sungai, masih dalam posisi duduk dalam sungai, lalu mengambil 3 butir batu, lalu mandi sendiri, dengan cara, kepala dimasukkan ke dalam air, lalu menggunakan kedua tangannnya menyiram air ke bagaian kepala, kemudian setelah itu posisi berdiri di sungai, lalu ke tiga batu yang diambil didasar sungai tadi dilemparkan ke belakang ke arah aliran sungai sambil mengucapkan kalimat, "mohonem kou, na'am lumalalas be si ahu", 'pergilah kau jangan lagi engkau mengikuti aku'. 
5. Selanjutnya keluar dari sungai berganti pakaian. Pakaian yang sudah basah dibungkus dan dibawa pulang ke rumah. Selama kegiatan mulai keluar dari sungai, mengambi baju ganti, memakai sampai siap untuk pulang, tidak boleh menoleh ke belakang. Dalam perjalanan pulang ke rumah, yang harus dilakukan yaitu : berjalan sambil menundukkan kepala. Ketika bertemu dengan seseorang di tengah perjalanan pulang, dia tidak boleh menyapa atau membalas sapaan dari siapapun. Memang ada juga orang yang ditemui dalam perjalanan pulang yang tidak tahu dengan tradisi ini, sehingga mereka akan menegur atau menyapa orang yang dimandikan. Tetapi kalau bertemu dengan orang yang sudah tahu bahwa orang yang mereka temui sementara mengikuti prosesi kegiatan pinə?danoan ini, maka dia tidak akan menyapa atau menegur. Itulah sebabnya kegiatan memandikan disungai ini harus dilakukan pada subuh untuk meminimalisir pertemuan dengan orang lain sewaktu jalan pulang ke rumah. Selain itu, ketika mandi di sungai ilakukan pada waktu subuh, memungkinkan air sungai tersebut masih bersih, dalam pengertiannya belum ada orang lain yang menggunakan air sungai tersebut untuk mandi mencuci dan lain sebagainya. Kegiatan tradisi "PinəPdanoan" ini dilakukan selama 3 kali di hari yang berbeda.

\section{Faktor-Faktor Penyebab}

Terdapat beberapa penyebab dari kegiatan tradisi ini, ialah:

a. Faktor Kosmologi Minahasa.

Faktor yang menyebabkan masih dilaksanakan tradisi "Pinə?danoan"sesudah acara Pemakaman jenazah pada masyarakat di Tombatu, yatu faktor Kosmologi Minahasa. Kosmologi berasal dari bahasa Yunani,kosmos yang berarti "dunia" dan logos artinya "Ilmu". Secara umum, kosmologi merujuk pada ilmu tentang alam sesmesta sebagai sisitem yang rasional dan teratur. Kosmologi hadir sebagai upaya manusia dalam memahami alam semesta kemudian menentukan posisi didalamnya. Hal ini didasari pada adanya keyakinan manusia bahwa, dibalik gerakan-gerakan planet yang kelihatannya kacau, pasti ada pola nyata yang mengatur mekanisme tersebut. Pandangan Kosmologis ini menyiratkan bahwa alam semesta sebagai subject matter pembahasan dalam kosmologi merupakan suatu "entitas"misterius yang mengandung sejuta rahasia dan tekateki, akan tetapi justru dari kemisteriusan alam semesta inilah muncul suatu keinginan manusia untuk memahami dan menentukan posisi di dalamnya. (lihat Imam Iqbal 2014: 28) . Para leluhur Orang Minahasa juga memandang alam sebagai subjeck matter dalam kehidupan sehari-hari yang berdampak pada pola pikir, sehingga menghasilkan tradisitradisi yang ada sekarang. Suku Tonsawang yang merupakan salah satu suku di Minahasa dipastikan menjadikan alam semesta sebagai subjeck matter.

\section{b. Faktor Kebaikan.}


Berdasarkan penuturan informan, masyarakat suku Tonsawang percaya bahwa, setiap keluarga baik antara ayah dan ibu, antara ayah dan anak-anak, antara ibu dan anak-anak serta antara anak, adik dan kakak,mempunyai suatu ikatan kasih sayang yang sangat kuat, dan mempunyai keterikatan batin yang sangat dalam, serta mempunyai ikatan darah. Mereka percaya ketika salah satu anggota keluarga mengalami musibah, misalnya kecelakaan, hingga kematian maka kontak batin dari anggota keluarga akan terguncang. Bahkan setelah kematianpun, ikatan batin ikatan darah antar anggota keluarga masih sangat berpengaru kuat. Menurut informan ketika mayat mulai membusuk, dan mulai terlepas dari tulang, maka anggota keluarga akan merasakan sakit seperti kecapekan yang sangat luar biasa. Mereka percaya bahwa arwah yang meninggal akan mengikuti anggota dimana pergi dan berada. Untuk itulah kegiatan "pinə?danoan dimandikan di sungai sangat perlu dilakukan untuk memutuskan ikatan batin antara orang yang meninggal dan anggota keluarga yang ditinggalkan. Dengan demikian bisa disimpulkan bahwa faktor kebaikan dilakukannya kegiatan tradisi "pinə?danoan" ini untuk mencegah keluarga inti yang ditinggalkan dari penyakit.

\section{c. Faktor Keburukan.}

Menurut Informan, setelah upacara pemakaman, jika kegiatan tradisi "pinə?danoan tidak dilakukan, dan pantangan-pantangan lainnya tidak dilakukan, maka selain sakit seperti badan merasa sangat capek, misalnya seorang suami yang meninggal, maka si istri harus mengikuti pantangan-pantangan dan tradisi "Pinə?danoan" . Mereka percaya jika tidak mengikuti kegiatan tersebut, maka hal buruk akan menimpah sang istri selain sakit kecapekan, akan mengalami sakit dalam bahasa Tonsawang disebut sakit "balu”. Ciri-ciri penyakit ini yaitu: si Istri ketika melihat lelaki yang menurut dia tampan, menarik baginya, maka dia akan memandang lelaki tersebut tanpa mengedipkan mata, memberikan senyuman manis, menggoda, meskipun sudah ditegur oleh orang lain. Dia seakan-akan menjadi tergila-gila dengan lelaki yang dia tatap, meskipun lelaki itu sudah berkeluarga, atau tidak menyukai kepada si janda. Suka tertawa dan tersenyum sendiri, tidak mau melakukan tugas kerjanya, pikirannya seakan-akan berada didalam dunia kayalan belaka. Nah hal ini akan menjadi aib bagi keluarga, yang mengakibatkan keluarga menjadi malu oleh karena perilaku aneh yang akan dilakukannya. Kalau yang meninggal si istri, maka si duda juga harus mengikuti kegiatan tradisi yang dilakukan istri. Termasuk pantangan-pantangannya. Jika tidak maka jenis penyakit yang dilami si janda, akan menimpah kepada si duda juga. Inilah Faktor keburukan yang akan dialami.

\section{Makna dilakukannya kegiatan tradisi "pinə?danoan"}

Berdasarkan penuturan para Informan, dilakukannya kegiatan tradisi "pinə?danoan " bermaksud untuk memutuskan ikatan batin, memutuskan dunia antara yang masih hidup dan yang telah meninggal, agar keluarga yang ditinggalkan terbebas dari pengaruh buruk arwah yang telah meninggal. Masyarakat suku Tonsawang percaya bahwa, selama 40 hari 
sejak meninggal arwah anggota kelurga yang telah meninggal akan terus mengikuti anggota, si arwah menggendongkan tubuhnya kepada keluarga inti yang ditinggalkan dan berdampak mudah sakit, mudah capek yang mengakibatkan seseorang menjadi malas untuk bekerja melanjutkan tugas atau kerjanya. Hal ini dilakukan demi kebaikan kelanjutan hidup anggota keluarga yang ditinggalkan. Dengan demikian dapat disimpulkan bahwa, makna dilakukan kegiatan tradisi pinə?danoan untuk kebaikan dan kesejahteraan anggota keluarga yang masih hidup.

\section{Kesimpulan}

Berdasarkan uraian di atas, maka dapat disimpulkan sebagai berikut :

1. Tradisi "Pinə?danoan"sesudah acara Pemakaman jenazah pada masyarakat di Tombatu. Pemahaman masyarakat suku Tonsawang, tradisi "Pinə?danoan" ini merupakan tradisi yang harus dilakukan oleh keluarga inti yang telah mengalami duka. Orang yang bertugas memandikan disebut dengan "balian" pada sekira jam 4 atau jam 5 subuh menjemput orang atau keluarga yang berduka, dan bersama-sama menuju ke sungai untuk dimandikan. Proses pemandian keluarga/ orang yang berduka dilaksanakan berdasarkan pada kearifan lokal masyarakat suku Tonsawang. Tradisi ini dilakukan minimal selama 3 kali dihari yang berbeda dalam kurun sebelum 40 hari sejak anggota keluarga meninggal.

2. Faktor-faktor yang menyebabkan dilaksanakan tradisi "Pinə?danoan"sesudah acara Pemakaman jenazah pada masyarakat di Tombatu terdiri dari beberapa faktor yaitu faktor kosmologi Minahasa, Para leluhur Orang Minahasa memandang alam sebagai subjeck matter dalam kehidupan sehari-hari yang berdampak pada pola pikir, sehingga menghasilkan tradisitradisi yang ada sekarang. Suku Tonsawang yang merupakan salah satu suku di Minahasa dipastikan menjadikan alam semesta sebagai subjeck matter. Faktor kebaikan, yaitu dilakukannya kegiatan tradisi "pinə?danoan" ini untuk mencegah keluarga inti yang ditinggalkan dari penyakit. Faktor keburukan, masyarakat suku Tonsawang percaya jika tidak mengikuti kegiatan tersebut, maka hal buruk akan menimpah istri atau suami dan anakanak. Selain sakit kecapekan, akan mengalami sakit aneh, yang dalam bahasa Tonsawang disebut sakit "balu".

3. Kegiatan tradisi "pinə?danoan"dilakukannya mempunyai makna "bermaksud untuk memutuskan ikatan batin, memutuskan dunia, antara yang masih hidup dan yang telah meninggal, agar keluarga yang ditinggalkan terbebas dari pengaruh buruk arwah yang telah meninggal, dan dapat melanjutkan hidup dengan penuh damai. 


\section{Daftar Pustaka}

Ahimsa Putra .H.S 1985Etnosains dan Etnometodologi, Sebuah Perbandingan Masyarakat Indonesia XII(2) 103-104.

Comri.B. 1978. Aspects An Introduction to the Study of Verbal Aspect and Relation Program, Canbrige University Press

Ihromi, 2006,Pokok-Pokok Antropologi Budaya, Jakarta, Yayasan Obor Indonesia.

Koentjaraningrat,L 1979, Manusia dan Kebudayaan di Indonesia, Jakarta Jambatan

Spradly J.P. dan Marzali, 1979, A Methode Etnografi, PT Tiara Wacana Yokya.

Syam, Nur. 2012. Mazhab-Mazhab Antropologi . Yokyakarta: LKIS Printing Cemerlang. 